\title{
Use of folic acid and vitamin supplementation among adults with depression and anxiety: a cross-sectional, population-based survey
}

\author{
Guixiang Zhao*, Earl S Ford, Chaoyang Li, Kurt J Greenlund, Janet B Croft and Lina S Balluz
}

\begin{abstract}
Background: Evidence suggests that folate deficiency may be causatively linked to depressive symptoms. However, little is known on the status of use of folic acid and vitamin supplements among people with mental disorders. This study examined the prevalence and the likelihood of use of folic acid or vitamin supplements among adults with depression and anxiety in comparison to those without these conditions.

Methods: Using data from 46, 119 participants (aged $\geq 18$ years) in the 2006 Behavioral Risk Factor Surveillance System survey, we estimated the adjusted prevalence and odds ratios with 95\% confidence intervals for taking folic acid and vitamin supplements among those with ever diagnosed depression ( $n=8,019)$, ever diagnosed anxiety ( $n=5,546)$ or elevated depressive symptoms $(n=3,978$, defined as having a depression severity score of $\geq 10$ on the Patient Health Questionnaire-8 diagnostic algorithm).

Results: Overall, women were more likely than men to take folic acid supplements $1-4$ times/day (50.2\% versus $38.7 \%, \mathrm{P}<0.001)$ and vitamin supplements $(62.5 \%$ versus $49.8 \%, \mathrm{P}<0.001)$. After multivariate adjustment, men with ever diagnosed depression or anxiety were $42 \%$ and $83 \%$, respectively, more likely to take folic acid supplements < 1 time/day; $44 \%$ and 39\%, respectively, more likely to take folic acid supplements 1-4 times/day; and $40 \%$ and $46 \%$, respectively, more likely to take vitamin supplements compared to men without these conditions ( $P<0.05$ for all comparisons). Women with ever diagnosed depression were $13 \%$ more likely to take folic acid supplements 1-4 times/day and 15\% more likely to take vitamin supplements than women without this condition ( $\mathrm{P}<0.05$ for both comparisons). Use of folic acid and vitamin supplements did not differ significantly by elevated depressive symptoms in either sex.
\end{abstract}

Conclusion: The prevalence and the likelihood of taking folic acid and vitamin supplements varied substantially by a history of diagnosed depression among both men and women and by a history of diagnosed anxiety among men, but not by presence of elevated depressive symptoms in either sex.

Keywords: folic acid, vitamins, depression, anxiety, elevated depressive symptoms, BRFSS

\section{Background}

Depression is recognized as an important cause of disability and mortality worldwide [1,2]. Data from a populationbased survey in the United States showed that, in 2006, approximately $15.4 \%$ of adults aged $\geq 18$ years reported a history of diagnosed depression, $8.4 \%$ reported having moderate-to-severe depressive symptoms in the previous 2

\footnotetext{
* Correspondence: gzhao@cdc.gov

Division of Adult and Community Health, National Center for Chronic Disease Prevention and Health Promotion, Centers for Disease Control and
} Prevention, Atlanta, Georgia, USA

(C) 2011 Zhao et al; licensee BioMed Central Ltd. This is an Open Access article distributed under the terms of the Creative Commons Attribution License (http://creativecommons.org/licenses/by/2.0), which permits unrestricted use, distribution, and reproduction in any medium, provided the original work is properly cited. weeks, and $11.0 \%$ reported a history of diagnosed anxiety [3]. The burden of depression and other mental disorders in the United States is substantial and associated with a cost of $\$ 150$ billion each year [4].

Evidence suggests that folate deficiency is causatively linked to depressive symptoms because folate plays an important role in the one-carbon metabolic pathway involved in methylation processes and the synthesis of neurotransmitters in the central nervous system $[5,6]$. Elevated homocysteine levels, a marker of folate deficiency as well as vitamin B12 deficiency, can also cause oxidative 
stress, resulting in cerebral vascular and neurological damage and neurotransmitter deficiency $[7,8]$. To date, majority of cross-sectional studies, several prospective studies, and meta-analyses have shown that low levels of serum or red blood cell folate, low levels of serum vitamin B12, low dietary intake of folate and vitamin B12, and high levels of serum homocysteine are associated with an increased risk for depression [9-28]. Low folate levels have also been associated with severe depressive disorders and longer duration of depressive episodes [29]. In addition, depressed people with low serum folate levels are significantly less likely to respond to some antidepressant medications (such as fluoxetine) [30-32] and more likely to relapse during treatment [33]. In contrast, higher intakes of folate, vitamins B6 and B12 have been shown to be protective of depressive symptoms in some studies [34-36], but not in others [37].

The National Health and Nutrition Examination Survey (NHANES) data from 1999-2000 showed that 52\% of U.S. adults reported taking dietary supplements in the previous month and that $35 \%$ reported use of multivitamin-multimineral supplements [38]. However, the status of use of folic acid and vitamin supplements among people with depression is unknown. We hypothesized that use of these supplements may be positively associated with previously diagnosed depression; the currently elevated depressive symptoms may be inversely related to use of these supplements. To shed light on these questions, we examined the prevalence and the likelihood of taking folic acid and vitamin supplements among adults with depressive disorders in comparison with those without these conditions by using data from a population-based survey sample. In addition, because depression and anxiety often coexist in people with mental disorders [39], we also examined the prevalence and the likelihood of taking folic acid and vitamin supplements among adults with or without ever diagnosed anxiety, although associations of folate and B-vitamins with anxiety remain to be elucidated.

\section{Methods}

\section{Survey design, participants, and data}

Data for our analyses came from the Behavioral Risk Factor Surveillance System (BRFSS), a population-based telephone survey of health-related behaviors regarding the leading causes of death among noninstitutionalized U.S. adults aged $\geq 18$ years. The BRFSS is considered to be exempt from review by the Institutional Review Board of the Centers for Disease Control and Prevention. The BRFSS survey design, sampling methods and weights have been described elsewhere [40], and BRFSS data have consistently been found to provide valid and reliable estimates when compared with data from other national household surveys in the United States [40-42]. Further information on the BRFSS is available at http://www.cdc. gov/brfss/.

We analyzed the data collected from survey participants in 9 states (Delaware, Florida, Georgia, Minnesota, Missouri, Montana, Virginia, Wisconsin, and Wyoming) and Puerto Rico that had optional modules on folic acid and vitamin supplementation and on anxiety and depression in the 2006 BRFSS. The median cooperation rate (the percentage of eligible persons contacted who completed the interview) for the 2006 BRFSS was 74.5\%.

Use of vitamin supplements was assessed by asking participants whether they were currently taking any vitamin pills or supplements and their response to the question was dichotomized as yes/no. The use of folic acid supplements was assessed by asking participants whether they were taking folic acid supplements or taking multivitamins or any vitamin pills/supplements that contained folic acid and, if so, how many times a day they were taking such supplements. Their responses to the question were categorized as 1) not taking folic acid supplements, 2) taking folic acid supplements $<1$ time/day, and 3) taking folic acid supplements 1-4 times/day. Those who answered that they were taking folic acid supplements $>4$ times/day were excluded from the analyses because fewer than $0.5 \%$ of participants were in this category. Self-reports of vitamin and mineral supplement use have been reported to have high reliability and validity [43].

Participants' mental health status was assessed by asking them whether they had ever been told by a doctor or other healthcare provider that they had a depressive disorder (including depression, major or minor depression, or dysthymia) or an anxiety disorder (including acute or posttraumatic stress disorder, anxiety, generalized anxiety disorder, obsessive-compulsive disorder, panic disorder, phobia, or social anxiety disorder). Those who answered "yes" to either question were defined as having ever diagnosed depression or anxiety. Participants' current depressive symptoms were assessed using the Patient Health Questionnaire-8 (PHQ-8) diagnostic algorithm, which has been described in detail elsewhere $[3,44,45]$. Specifically, participants were asked about how many days in the previous 2 weeks they experienced each of the following symptoms of depression: 1) little interest or pleasure in doing things; 2) feeling down, depressed, or hopeless; 3) having trouble falling asleep or staying asleep or sleeping too much; 4) feeling tired or little energy; 5) having a poor appetite or eating too much; 6) feeling bad as a failure or letting themselves or their family down; 7) having trouble concentrating on things such as reading the newspaper or watching the TV; and 8) moving or speaking too slowly or being so fidgety or restless that they were moving around a lot more than usual. For each item, respondents scored as 0 point for $0-1$ day with reported symptoms, 1 point for 
2-6 days, 2 points for 7-11 days, and 3 points for 12-14 days. Their scores for each item were then added to produce a total depression severity score, and those with a total depression severity score of $\geq 10$ were defined as having elevated depressive symptoms (EDS). The PHQ-8 has been shown to provide valid measurements on major depression in the general population similar to that of the PHQ-9 (which includes the ninth question about thoughts of suicidality or self-injury) [46-49], and the scoring of $\geq$ 10 on the PHQ- 8 has been shown to have a sensitivity and specificity of $88 \%$ for major depression [47]. Currently, the reliability or validity of the measures for physician diagnosis of depression and anxiety in the BRFSS has not been determined due to lack of research. However, in psychiatric epidemiology, lifetime prevalence, estimated as the proportion of a sample having had at least one episode of mental disorders in their life prior to the survey, is one of the most commonly used parameters to assess history of mental disorders $[3,39,44,45]$. This measure reflects a view that most mental disorders are chronic conditions and symptomatic episodes of mental disorders are often interspersed with periods of remission.

The demographic variables in our analyses included respondents' age, sex, race/ethnicity (non-Hispanic white, non-Hispanic black, Hispanic, or other), education (< high school diploma, high school graduate, some college or technical school, or $\geq$ college graduate), marital status (married, divorced, never married, or other), and body mass index (BMI, self-reported weight divided by height in square). Respondents' smoking status was categorized as current smokers (participants who had smoked $\geq 100$ cigarettes during their lifetime and were still smoking), former smokers (those who had smoked $\geq 100$ cigarettes in their entire life but had stopped smoking), and never smokers (those who had never smoked or smoked $<100$ cigarettes during their lifetime). Leisure-time physical activity was assessed by asking respondents whether, during the previous month, they had participated in any physical activities or exercise other than their regular job. Heavy alcohol drinking was defined as women who had $>1$ drink/day or men who had $>2$ drinks/day during the previous 12 months.

\section{Statistical analyses}

Of a total of 55, 867 survey participants, after excluding from the analyses participants who responded "don't know/not sure, "refused to answer, or had missing responses for any of the questions described above, 46, 119 participants remained in our analyses. We estimated the adjusted prevalence of taking folic acid and vitamin supplements in adult men and women. We tested the interactive effects of sex with all three mental disorders on the outcome measurements (i.e., use of folic acid and vitamin supplements) in the fully adjusted models which included the main effects of sex and mental disorders. The interaction terms were significant so we conducted sex-stratified analysis. Adjusted prevalence (predicted marginal probability) of taking folic acid and vitamin supplements was estimated by conducting logistic regression analyses after adjustment for age, race/ethnicity, education, body mass index, marital status, smoking status, leisure-time physical activity, and heavy alcohol drinking. We also estimated the adjusted odds ratios (AORs) with 95\% confidence intervals (CIs) for taking folic acid and vitamin supplements using mental disorders as exposure variables while controlling for demographic variables and lifestyle factors as listed above. We used SUDAAN, 9.0 (Research Triangle Institute, Research Triangle Park, NC) to account for the multistage, disproportionate stratified sampling design.

\section{Results}

Of the 46, 119 participants, the age-adjusted prevalence of ever diagnosed depression was $15.0 \%$ [men-10.4\% versus women-19.4\% ( $\mathrm{P}<0.001)$, the age-adjusted prevalence of ever diagnosed anxiety was $11.2 \%$ [men-8.2\% versus women-14.1\% ( $\mathrm{P}<0.001)]$, and the age-adjusted prevalence of EDS was $8.3 \%$ [men-6.5\% versus women-10.0\% $(\mathrm{P}<0.001)]$. The mean age of participants was 45.8 years, and the mean BMI was $27.1 \mathrm{~kg} / \mathrm{m}^{2}$. Approximately $49.2 \%$ of participants were men, $61.6 \%$ were married, and $34.6 \%$ had an education of $\geq$ college graduate. By race/ethnicity, $70.9 \%$ were non-Hispanic white, $9.5 \%$ were non-Hispanic black, $14.7 \%$ were Hispanic, and $4.9 \%$ were of "other" race/ ethnicity.

Participants with any of the three categories of mental disorder were significantly younger than those without $(\mathrm{P}<0.001$ for all) (Table 1$)$. The weighted percentages of participants who were male, married, or $\geq$ college graduates were significantly lower $(\mathrm{P}<0.01$ for all), and the weighted percentages of adults who were obese were significantly higher $(\mathrm{P}<0.001)$, among those with mental disorders than among those without these conditions (Table 1).

Overall, after multivariate adjustment for age, race/ethnicity, education, marital status, BMI, smoking status, leisure-time physical activity, and heavy alcohol drinking, women had a significantly higher prevalence of taking folic acid supplements $1-4$ times/day (50.2\% versus $38.7 \%, \mathrm{P}<$ 0.001; AOR:1.74, 95\% CI:1.63-1.86) or taking vitamin supplements $(62.5 \%$ versus $49.8 \%, \mathrm{P}<0.001$; AOR:1.76, $96 \%$ CI:1.64-1.89) than men. In our logistic regression models, we stratified data analyses by sex because of the significant interactive effects of sex and mental disorders on the outcome measurements. Compared with men without diagnosed depression and anxiety, those with a history of these diagnoses had a significantly higher prevalence of taking folic acid supplements 1-4 times/day, and significantly 
Table 1 Demographic characteristics of study population $(N=46,119)$ by depression and anxiety status, BRFSS, 2006*

\begin{tabular}{|c|c|c|c|c|c|c|}
\hline & \multicolumn{2}{|c|}{ Ever diagnosed depression } & \multicolumn{2}{|c|}{ Ever diagnosed anxiety } & \multicolumn{2}{|c|}{ EDS } \\
\hline & $\begin{array}{c}\text { yes } \\
\mathrm{n}=8,019\end{array}$ & $\begin{array}{c}\text { no } \\
\mathrm{n}= \\
\mathbf{3}\end{array}$ & $\begin{array}{c}\text { yes } \\
\mathrm{n}=5,546\end{array}$ & $\begin{array}{c}\text { no } \\
n=40,573\end{array}$ & $\begin{array}{c}\text { yes } \\
\mathrm{n}=3,978\end{array}$ & $\begin{array}{c}\text { no } \\
n=42,141\end{array}$ \\
\hline Age (years) & $44.4(0.3)$ & $46.0(0.2)$ & $43.7(0.4)$ & $46.0(0.2)$ & $42.0(0.5)$ & $46.1(0.2)$ \\
\hline \multicolumn{7}{|l|}{ Sex } \\
\hline Men & $34.4(1.0)$ & $51.8(0.4)$ & $36.1(1.2)$ & $50.9(0.4)$ & $38.8(1.6)$ & $50.2(0.4)$ \\
\hline Women & $65.6(1.0)$ & $48.2(0.4)$ & $63.9(1.2)$ & $49.1(0.4)$ & $61.2(1.6)$ & $49.8(0.4)$ \\
\hline \multicolumn{7}{|l|}{ Race/ethnicity } \\
\hline Non-Hispanic white & $75.1(0.8)$ & $70.2(0.4)$ & $72.0(1.0)$ & $70.8(0.4)$ & $64.4(1.5)$ & $71.5(0.4)$ \\
\hline Non-Hispanic black & $6.8(0.6)$ & $10.0(0.3)$ & $7.2(0.7)$ & $9.8(0.3)$ & $11.5(1.0)$ & $9.3(0.2)$ \\
\hline Hispanic & $13.4(0.6)$ & $14.9(0.3)$ & $15.5(0.8)$ & $14.6(0.3)$ & $18.0(1.2)$ & $14.4(0.3)$ \\
\hline Others & $4.8(0.4)$ & $4.9(0.2)$ & $5.2(0.5)$ & $4.8(0.2)$ & $6.1(0.7)$ & $4.8(0.2)$ \\
\hline \multicolumn{7}{|l|}{ Education } \\
\hline$<$ high school diploma & $11.4(0.7)$ & $9.2(0.2)$ & $13.0(0.8)$ & $9.1(0.2)$ & $21.1(1.3)$ & $8.5(0.2)$ \\
\hline High school graduate & $29.1(0.9)$ & $28.1(0.4)$ & $28.8(1.1)$ & $28.2(0.4)$ & $33.5(1.4)$ & $27.8(0.4)$ \\
\hline Some college/technical & $29.4(0.9)$ & $27.3(0.4)$ & $29.2(1.1)$ & $27.4(0.4)$ & $27.9(1.4)$ & $27.6(0.4)$ \\
\hline$\geq$ College graduate & $30.1(0.9)$ & $35.4(0.4)$ & $29.0(1.0)$ & $35.3(0.4)$ & $17.5(1.1)$ & $36.1(0.4)$ \\
\hline \multicolumn{7}{|l|}{ Body mass index $\left(\mathrm{kg} / \mathrm{m}^{2}\right)$} \\
\hline$<25.0$ & $36.1(1.0)$ & $38.7(0.4)$ & $37.7(1.2)$ & $38.4(0.4)$ & $34.7(1.5)$ & $38.6(0.4)$ \\
\hline $25.0-<30.0$ & $31.7(0.9)$ & $37.7(0.4)$ & $33.1(1.1)$ & $37.2(0.4)$ & $29.5(1.4)$ & $37.4(0.4)$ \\
\hline$\geq 30.0$ & $32.2(0.9)$ & $23.7(0.4)$ & $29.2(1.0)$ & $24.4(0.4)$ & $35.8(1.3)$ & $24.0(0.3)$ \\
\hline \multicolumn{7}{|l|}{ Marital status } \\
\hline Married & $50.7(1.0)$ & $63.5(0.4)$ & $51.0(1.2)$ & $62.9(0.4)$ & $42.4(1.4)$ & $63.3(0.4)$ \\
\hline Divorced & $15.0(0.6)$ & $8.0(0.2)$ & $14.1(0.6)$ & $8.4(0.2)$ & $14.8(0.8)$ & $8.5(0.2)$ \\
\hline Never married & $18.4(1.0)$ & $17.4(0.4)$ & $20.2(1.2)$ & $17.2(0.4)$ & $23.0(1.6)$ & $17.1(0.4)$ \\
\hline Others & $15.8(0.7)$ & $11.1(0.2)$ & $14.7(0.8)$ & $11.5(0.2)$ & $19.8(1.3)$ & $11.1(0.2)$ \\
\hline
\end{tabular}

* Data presented as weighted percentages with standard errors in parentheses except for mean age. BRFSS = Behavioral Risk Factor Surveillance System, EDS = Elevated depressive symptoms

higher AORs for taking folic acid supplements at both levels ( $<1$ time/day or $1-4$ times/day) $(\mathrm{P}<0.05$ or $\mathrm{P}<$ 0.001 , Table 2). Women with ever diagnosed depression were also significantly more likely than women without this condition to take folic acid supplements 1-4 times/day (52.7\% versus $49.8 \%, \mathrm{P}<0.05$; AOR: 1.13 , 95\% CI: $1.02-$ 1.26). Similarly, men with ever diagnosed depression (56.5\% versus $48.8 \%, \mathrm{P}<0.001$; AOR: $1.40,95 \% \mathrm{CI}: 1.18-$ $1.66)$ or anxiety $(57.5 \%$ versus $49.0 \%, \mathrm{P}<0.001$; AOR: 1.46, 95\% CI: 1.18-1.80) and women with ever diagnosed depression (65.0\% versus $62.0 \%, \mathrm{P}<0.01$; AOR: $1.15,95 \%$ CI: 1.04-1.28) were significantly more likely to report taking vitamin supplements than those who had never been diagnosed with these conditions after adjustment for multiple demographic variables and lifestyle factors (Table 3). No significant associations of EDS with taking folic acid and vitamin supplements were observed in either sex (Table 2 and Table 3).

For depression status, people who were ever diagnosed with depression may or may not have EDS currently -this may have affected their behaviors of taking dietary supplements. Thus, we conducted further stratified analysis by ever diagnosed depression and/or EDS. A total of 5, 657 participants [the age-adjusted prevalence: total-10.6\%; men-7.4\% versus women-13.6\% $(\mathrm{P}<0.001)]$ reported having ever diagnosed depression only, 1, 616 [the ageadjusted prevalence: total-3.9\%; men-3.4\% versus women4.3\% $(\mathrm{P}<0.05)$ ] reported having EDS only, and 2, 362 [the age-adjusted prevalence: total-4.4\%; men-3.1\% versus women-5.6\% $(\mathrm{P}<0.001)$ ] reported having both. Compared with men having neither ever diagnosed nor EDS, those with ever diagnosed depression, regardless whether they had EDS currently, were significantly more likely to take folic acid supplements 1-4 times/day (AOR: 1.48, 95\% CI: 1.22-1.81 for those with ever diagnosed depression only and AOR: 1.31, 95\% CI: 0.99-1.80 for those with both ever diagnosed depression and EDS) and to take vitamin supplements (AOR: 1.40, 95\% CI: 1.16-1.69 for those with ever diagnosed depression only and AOR: 1.39, 95\% CI: 1.00-1.92 for those with both ever diagnosed depression and EDS) (Figure 1 and Figure 2). Women with ever diagnosed depression but without EDS were also significantly more likely to take folic acid supplements 1-4 times/day (AOR: 1.13, 95\% CI: 1.01-1.28) and to take vitamin supplements (AOR: 1.20, 95\% CI: 1.06-1.36) than were women with neither conditions (Figure 1 and Figure 2); however, 
Table 2 Adjusted prevalence (with standard error) of and adjusted odds ratios (with $95 \%$ confidence intervals) for taking folic acid supplements among adults aged $\geq 18$ years, by sex and by depression and anxiety status, BRFSS, 2006

\begin{tabular}{|c|c|c|c|c|c|c|c|}
\hline \multirow{4}{*}{ (times/day) } & \multicolumn{3}{|c|}{ Adjusted prevalence* } & \multirow{2}{*}{\multicolumn{4}{|c|}{$\begin{array}{l}\text { Adjusted odds ratio* } \\
\text { Taking supplements }\end{array}$}} \\
\hline & \multicolumn{2}{|c|}{ Taking supplements } & \multirow[t]{2}{*}{ No supplements } & & & & \\
\hline & \multirow{2}{*}{$\begin{array}{c}<1 \\
\%(\mathrm{SE})\end{array}$} & 1 to 4 & & \multicolumn{2}{|c|}{$<1$} & \multicolumn{2}{|r|}{1 to 4} \\
\hline & & $\%$ (SE) & $\%$ (SE) & AOR & $95 \% \mathrm{Cl}$ & AOR & $95 \% \mathrm{Cl}$ \\
\hline \multicolumn{8}{|l|}{ Men $(n=18,092)$} \\
\hline \multicolumn{8}{|c|}{ Ever diagnosed depression } \\
\hline Yes $(n=2,140)$ & $7.6(1.1)$ & $45.1(1.8) \emptyset$ & $47.3(1.9) 9$ & 1.42 & $1.00-2.00$ & 1.44 & $1.21-1.71$ \\
\hline No $(n=15,952)$ & $6.4(0.4)$ & $38.0(0.6)$ & $55.6(0.6)$ & 1.00 & & 1.00 & \\
\hline \multicolumn{8}{|l|}{ Ever diagnosed anxiety } \\
\hline Yes $(n=1,508)$ & $9.6(1.8) \dagger$ & $43.6(2.2) \neq$ & $46.8(2.3) \uparrow$ & 1.83 & $1.18-2.84$ & 1.39 & $1.13-1.70$ \\
\hline No $(n=16,584)$ & $6.3(0.4)$ & $38.3(0.6)$ & $55.4(0.6)$ & 1.00 & & 1.00 & \\
\hline \multicolumn{8}{|l|}{ EDS } \\
\hline Yes $(n=1,162)$ & $10.6(2.7)$ & $37.5(2.4)$ & $52.0(3.1)$ & 1.79 & $0.96-3.34$ & 1.02 & $0.80-1.30$ \\
\hline No $(n=16,930)$ & $6.3(0.4)$ & $38.8(0.6)$ & $54.9(0.6)$ & 1.00 & & 1.00 & \\
\hline \multicolumn{8}{|l|}{ Women $(n=28,027)$} \\
\hline \multicolumn{8}{|c|}{ Ever diagnosed depression } \\
\hline Yes $(n=5,879)$ & $6.6(0.6)$ & $52.7(1.1) \neq$ & 40.7 (1.0)‡ & 0.97 & $0.76-1.24$ & 1.13 & $1.02-1.26$ \\
\hline No $(n=22,148)$ & $7.2(0.3)$ & $49.8(0.5)$ & $43.0(0.5)$ & 1.00 & & 1.00 & \\
\hline \multicolumn{8}{|l|}{ Ever diagnosed anxiety } \\
\hline Yes $(n=4,038)$ & $7.0(0.8)$ & $51.8(1.3)$ & $41.3(1.2)$ & 1.02 & $0.78-1.33$ & 1.08 & $0.96-1.22$ \\
\hline No $(n=23,989)$ & $7.1(0.3)$ & $50.1(0.5)$ & $42.8(0.5)$ & 1.00 & & 1.00 & \\
\hline \multicolumn{8}{|l|}{ EDS } \\
\hline Yes $(n=2,816)$ & $7.5(1.2)$ & $49.2(1.6)$ & $43.2(1.5)$ & 1.05 & $0.73-1.51$ & 0.96 & $0.83-1.10$ \\
\hline No $(n=25,211)$ & $7.0(0.3)$ & $50.5(0.5)$ & $42.5(0.5)$ & 1.00 & & 1.00 & \\
\hline
\end{tabular}

${ }^{*}$ Adjusted for age, race/ethnicity, education, body mass index, marital status, smoking, leisure-time exercise, and alcohol consumption. $† P=0.065$, $\neq P<0.05$, and IP $<0.001$ for comparisons between adults with ever diagnosed depression or anxiety and those without. AOR $=$ Adjusted odds ratio, BRFSS $=$ Behavioral Risk Factor Surveillance System, $\mathrm{Cl}=$ Confidence interval, EDS = Elevated depressive symptoms, SE = Standard error

these associations were not significant in women with both ever diagnosed depression and EDS.

\section{Discussion}

Our results showed that, among participants from 9 states and 1 territory of the United States, use of folic acid supplements $1-4$ times/day (50.2\% versus $38.7 \%)$ and use of vitamin supplements (62.5\% versus $49.8 \%)$ were significantly higher among women than among men. Men with ever diagnosed depression were more likely to report taking folic acid and vitamin supplements than men with no history of diagnosed depression regardless whether they had elevated depressive symptoms. In contrast, although women with ever diagnosed depression were significantly more likely to report taking folic acid 1-4 times/day and vitamin supplements than were women with no history of diagnosed depression, these differences were no longer statistically significant when the status on elevated depressive symptoms was taken into consideration.

To date, most previous studies have mainly focused on the causal relationship between folate and mental disorders. The results of these studies suggest that folate or folinic acid (5-methyltetrahydrofolate) may serve as a stand-alone treatment of depression [50,51] or an augmentation of antidepressant treatment showing a significant beneficial effect in reducing Hamilton Depression Rating Scale Score when used with other psychotropic medication [52-57]. Limited evidence from the Vitamins and Lifestyle (VITAL) study showed that $10.4 \%$ of participants with depression who were taking medications for depression reported taking dietary supplements and that $6.7 \%$ of those who felt depressed or anxious but did not take medication for depression reported doing so [58]. In that study, participants were limited to the 50 to 75 years of age, and dietary supplements were a combination of 17 supplements including folic acid and various other vitamins. To our knowledge, our study is the first populationbased study to focus on the behaviors of use of folic acid and vitamin supplements among adults with depression or anxiety. Although our results showed that men with ever diagnosed depression or anxiety and women with ever diagnosed depression were more likely than those without a history of these conditions to report taking folic acid supplements (1-4 times/day), only about $50 \%$ of them were doing so. Most importantly, we found that adults 
Table 3 Adjusted prevalence (with standard error) of and adjusted odds ratios (with $95 \%$ confidence intervals) for taking vitamin supplements among adults aged $\geq 18$ years, by sex and by depression and anxiety status, BRFSS, 2006

\begin{tabular}{|c|c|c|c|}
\hline & \multirow{2}{*}{$\begin{array}{c}\text { Adjusted prevalence* } \\
\%(\mathrm{SE})\end{array}$} & \multicolumn{2}{|c|}{ Adjusted odds ratio* } \\
\hline & & AOR & $95 \% \mathrm{Cl}$ \\
\hline \multicolumn{4}{|l|}{ Men $(n=18,497)$} \\
\hline \multicolumn{4}{|c|}{ Ever diagnosed depression } \\
\hline Yes $(n=2,140)$ & $56.5(1.8) 9$ & 1.40 & $1.18-1.66$ \\
\hline No $(n=15,952)$ & $48.8(0.6)$ & 1.00 & \\
\hline \multicolumn{4}{|l|}{ Ever diagnosed anxiety } \\
\hline Yes $(n=1,508)$ & $57.5(2.3) 9$ & 1.46 & $1.18-1.80$ \\
\hline No $(n=16,584)$ & $49.0(0.6)$ & 1.00 & \\
\hline \multicolumn{4}{|l|}{ EDS } \\
\hline Yes $(n=1,162)$ & $52.1(3.1)$ & 1.12 & $0.86-1.47$ \\
\hline No $(n=16,930)$ & $49.5(0.6)$ & 1.00 & \\
\hline \multicolumn{4}{|l|}{ Women $(n=28,332)$} \\
\hline \multicolumn{4}{|c|}{ Ever diagnosed depression } \\
\hline Yes $(n=5,879)$ & $65.0(1.0) \S$ & 1.15 & $1.04-1.28$ \\
\hline No $(n=22,148)$ & $62.0(0.5)$ & 1.00 & \\
\hline \multicolumn{4}{|l|}{ Ever diagnosed anxiety } \\
\hline Yes $(n=4,038)$ & $64.0(1.2)$ & 1.08 & $0.95-1.22$ \\
\hline No $(n=23,989)$ & $62.4(0.5)$ & 1.00 & \\
\hline \multicolumn{4}{|l|}{ EDS } \\
\hline Yes $(n=2,816)$ & $61.2(1.5)$ & 0.92 & $0.80-1.07$ \\
\hline No $(n=25,211)$ & $62.8(0.5)$ & 1.00 & \\
\hline
\end{tabular}

*Adjusted for age, race/ethnicity, education, body mass index, marital status, smoking, leisure-time physical activity, and alcohol consumption. § $\mathrm{P}<0.01$, $\mathrm{P}<<$ 0.001 for comparisons between adults with ever diagnosed depression or anxiety and those without. AOR $=$ Adjusted odds ratio, BRFSS $=$ Behavioral Risk Factor Surveillance System, $\mathrm{Cl}=$ Confidence interval, EDS = Elevated depressive symptoms, $\mathrm{SE}=$ Standard Error

with elevated depressive symptoms were only as likely as those without these symptoms to report taking folic acid supplements. At present, studies have consistently reported a high prevalence of depressive symptoms in populations $[3,45,59]$, and these symptoms are strongly associated with first-onset major depression [59]. In addition, most depressive symptoms are often unrecognized and untreated in clinical practice. Given the links between folate deficiency and depressive symptoms [9-28], the use of folic acid supplements may possibly prevent or delay the onset of major depression among people with elevated depressive symptoms, although randomized trials are needed to confirm it.

Other than folate, studies have shown that low levels of vitamin B6 and B12 were also related to depressive disorders $[16,19,23,26,27,60-62]$, however, other studies failed to show any relationship between vitamin B12 and depressive symptoms $[12,20,25,30]$. Similarly, high intakes of vitamins B6 and B12 have shown to be protective of depressive symptoms in a prospective study [36], but not in others $[34,37]$. Thus, the controversial results remained to be elucidated in the future. Nonetheless, B-vitamins including B6 and B12 have known to be important for essential functioning of the one-carbon metabolism in the biosynthesis of monoamine neurotransmitters including serotonin, dopamine, norepinephrine, and epinephrine
[60-62], all of which are known to affect mood and cognition. Our results showed that, although adults with ever diagnosed depression were significantly more likely to report taking vitamin supplements than those with no history of diagnosed depression, only less than two-thirds of them reported taking vitamin supplements. Taken together, our results call for further research or clinical trials that may help to establish whether the use of folic acid and vitamin supplements should be improved among people with mental disorders.

Our results further demonstrated that men with ever diagnosed anxiety were significantly more likely to report taking folic acid and vitamin supplements, although these relationships were not observed among women with anxiety. At present, the relationship between anxiety and use of folic acid and vitamin supplementats is unknown. However, given the high prevalence of anxiety in the U.S. population $[3,45]$ and its coexistence with depression [39], further investigation of the role of folic acid and vitamin supplementation in the prevention and treatment of anxiety is needed.

There are several limitations in the present study. First, all data were based on the self-reports by survey participants and thus subject to recall bias. Second, the information on the severity and diagnosis date of mental disorders was not available in the BRFSS. Third, given 

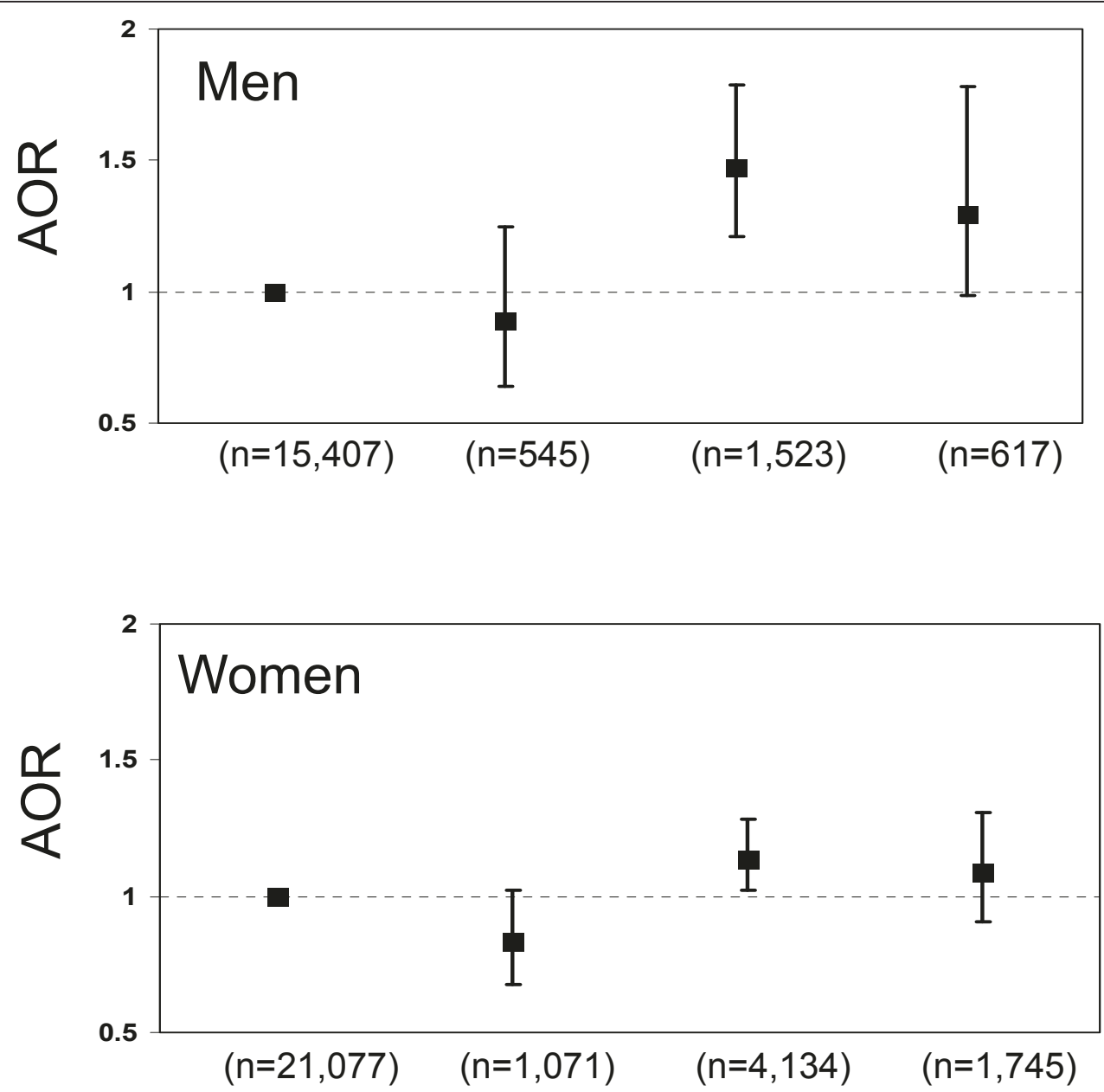

\section{Ever diagnosed depression}

\section{EDS}

no

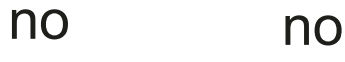

yes yes

no

\section{yes}

\section{yes}

Figure 1 Adjusted odds ratios (with 95\% confidence intervals) for taking folic acid supplements 1-4 times/day among men (top) and women (bottom) aged $\geq 18$ years with either ever diagnosed depression or elevated depressive symptoms (EDS) or both.

the cross-sectional nature of the survey, the temporal relationship between the use of folic acid and vitamin supplements and the presence of depression, anxiety, or elevated depressive symptoms cannot be established in the present study. Evidence suggests that folate/vitamin deficiency may affect one-carbon metabolic pathway and neurotransmitter synthesis in the central nervous system, thereby linking to depressive disorders. On the other hand, people who are diagnosed with mental disorders may be more likely to take dietary supplements. Thus, bidirectional associations may exist. Fourth, although we have assessed the frequency of folic acid supplementation, the amount of daily folic acid and vitamin intake as well as the biomarkers of folic acid and vitamin supplementation (i.e., serum or red blood cell folate levels, serum homocysteine levels, or serum vitamin levels) was unknown in the present study. Also, data on dietary intake of folate and vitamins as well as dietary energy intake were not available in the BRFSS so we were unable to assess whether these variables may have confounding effects. Fifth, women of reproductive age may be more likely to take folic acid and vitamin supplements. In addition, people with chronic conditions such as cardiovascular disease and diabetes may confer higher risks for depression. Thus, further stratified analysis in women of childbearing age or in people with chronic conditions are 

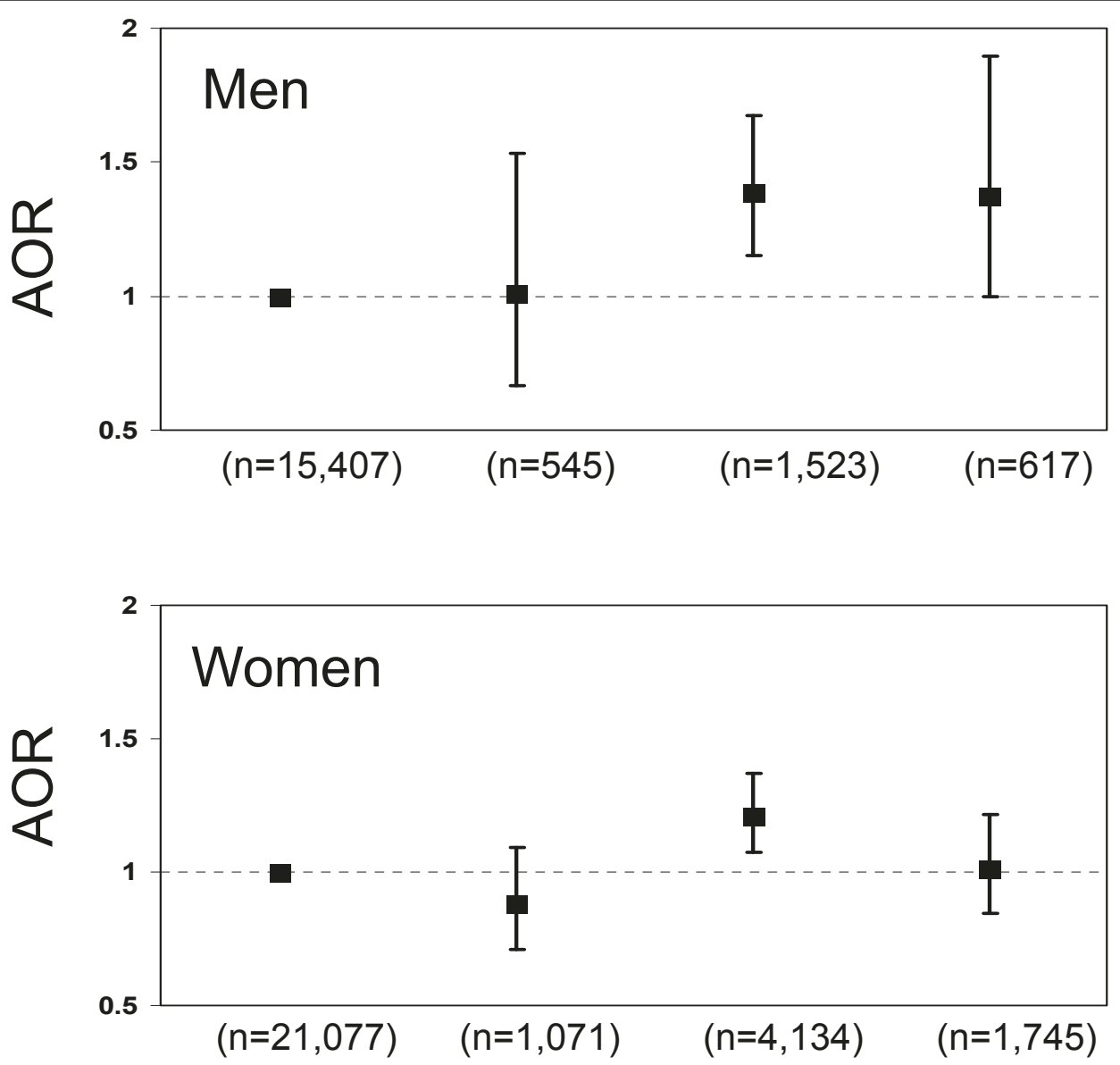

\section{Ever diagnosed depression}

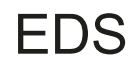

\section{no}

no no

yes yes

no yes

yes

Figure 2 Adjusted odds ratios (with 95\% confidence intervals) for taking vitamin supplements among men (top) and women (bottom) aged $\geq 18$ years with either ever diagnosed depression or elevated depressive symptoms (EDS) or both.

warranted in future studies. Finally, use of prescribed medications (including prescribed folate or other supplements that contain folate) for depression, anxiety, or other mental disorders was not ascertained, thus, we were unable to conduct stratified analyses by medication use.

\section{Conclusions}

Our results from a large, nationally representative sample demonstrated that substantial variations exist in the prevalence and the likelihood of taking folic acid and vitamin supplements by sex and by histories of previously diagnosed depression and anxiety, but not by presence of elevated depressive symptoms. Our results provide fundamental information on the status of dietary supplement use among U.S. adults with mental disorders, and have important implications in public health nutrition given that high intakes of folic acid and vitamins may reduce the risk for depressive disorders [34-36] and increase medication response in depressed patients [52-57].

\section{Sources of financial support}

None.

\section{Abbreviations}

AOR: Adjusted odds ratio; BMI: Body mass index; BRFSS: Behavioral Risk Factor Surveillance System; Cl: Confidence interval; EDS: Elevated depressive symptoms; NHANES: National Health and Nutrition Examination Survey; PHQ: Patient Health Questionnaire; SE: Standard error; VITAL: Vitamins and Lifestyle. 


\section{Acknowledgements}

Disclaimer: The findings and conclusions in this article are those of the authors and do not necessarily represent the official position of the Centers for Disease Control and Prevention.

\section{Authors' contributions}

GZ conducted the data analyses, interpreted the data, and prepared the manuscript. ESF supervised the data analyses and contributed to the manuscript writing. ESF, CL, KJG, JBC, and LSB made critical revisions of the manuscript for important intellectual content. All authors have read and approved the final version of the manuscript.

\section{Competing interests}

The authors declare that they have no competing interests.

Received: 19 January 2011 Accepted: 30 September 2011 Published: 30 September 2011

\section{References}

1. Murray CJ, Lopez AD: Global mortality, disability, and the contribution of risk factors: Global Burden of Disease Study. Lancet 1997, 349:1436-1442.

2. Murray CJ, Lopez AD: Alternative projections of mortality and disability by cause 1990-2020: Global Burden of Disease Study. Lancet 1997, 349:1498-1504

3. Zhao G, Ford ES, Dhingra S, Li C, Strine TW, Mokdad AH: Depression and anxiety among US adults: associations with body mass index. Int J Obes (Lond) 2009, 33:257-266.

4. President's New Freedom Commission on Mental Health (US): Achieving the promise: transforming mental health care in America Rockville (MD): Department of Health and Human Services, US; 2003.

5. Coppen A, Bolander-Gouaille C: Treatment of depression: time to consider folic acid and vitamin B12. J Psychopharmacol 2005, 19:59-65.

6. Miller AL: The methylation, neurotransmitter, and antioxidant connections between folate and depression. Altern Med Rev 2008, 13:216-226.

7. Bottiglieri T, Laundy M, Crellin R, Toone BK, Carney MW, Reynolds EH: Homocysteine, folate, methylation, and monoamine metabolism in depression. J Neurol Neurosurg Psychiatry 2000, 69:228-232.

8. Folstein M, Liu T, Peter I, Buell J, Arsenault L, Scott T, Qiu WW: The homocysteine hypothesis of depression. Am J Psychiatry 2007, 164:861-867.

9. Abou-Saleh MT, Coppen A: Serum and red blood cell folate in depression. Acta Psychiatr Scand 1989, 80:78-82.

10. Almeida OP, McCaul K, Hankey GJ, Norman P, Jamrozik K, Flicker L: Homocysteine and depression in later life. Arch Gen Psychiatry 2008, 65:1286-1294.

11. Astorg P, Couthouis A, de Courcy GP, Bertrais S, Arnault N, Meneton P, Galan P, Hercberg S: Association of folate intake with the occurrence of depressive episodes in middle-aged French men and women. $\mathrm{Br} J$ Nutr 2008, 100:183-187.

12. Beydoun MA, Shroff MR, Beydoun HA, Zonderman AB: Serum folate, vitamin B-12, and homocysteine and their association with depressive symptoms among U.S. adults. Psychosom Med 2010, 72:862-873.

13. Beydoun MA, Fanelli Kuczmarski MT, Beydoun HA, Shroff MR, Mason MA, Evans MK, Zonderman AB: The sex-specific role of plasma folate in mediating the association of dietary quality with depressive symptoms. J Nutr 2010, 140:338-347.

14. Bjelland I, Tell GS, Vollset SE, Refsum H, Ueland PM: Folate, vitamin B12, homocysteine, and the MTHFR $677 \mathrm{C}->\mathrm{T}$ polymorphism in anxiety and depression: the Hordaland Homocysteine Study. Arch Gen Psychiatry 2003, 60:618-626.

15. Carney MW, Chary TK, Laundy M, Bottiglieri T, Chanarin I, Reynolds EH, Toone B: Red cell folate concentrations in psychiatric patients. J Affect Disord 1990, 19:207-213.

16. Dimopoulos N, Piperi C, Salonicioti A, Psarra V, Gazi F, Papadimitriou A, Lea RW, Kalofoutis A: Correlation of folate, vitamin B12 and homocysteine plasma levels with depression in an elderly Greek population. Clin Biochem 2007, 40:604-608.

17. Forti P, Rietti E, Pisacane N, Olivelli V, Dalmonte E, Mecocci P, Ravaglia G Blood homocysteine and risk of depression in the elderly. Arch Gerontol Geriatr 2010, 51:21-25.
18. Gilbody S, Lightfoot T, Sheldon T: Is low folate a risk factor for depression? A meta-analysis and exploration of heterogeneity. $J$ Epidemiol Community Health 2007, 61:631-637.

19. Kim JM, Stewart R, Kim SW, Yang SJ, Shin IS, Yoon JS: Predictive value of folate, vitamin B12 and homocysteine levels in late-life depression. $\mathrm{Br} \mathrm{J}$ Psychiatry 2008, 192:268-274.

20. Lerner V, Kanevsky M, Dwolatzky T, Rouach T, Kamin R, Miodownik C: Vitamin B12 and folate serum levels in newly admitted psychiatric patients. Clin Nutr 2006, 25:60-67.

21. Morris MS, Fava M, Jacques PF, Selhub J, Rosenberg $\mid \mathrm{H}$ : Depression and folate status in the US Population. Psychother Psychosom 2003, 72:80-87.

22. Nanri A, Mizoue T, Matsushita Y, Sasaki S, Ohta M, Sato M, Mishima N: Serum folate and homocysteine and depressive symptoms among Japanese men and women. Eur J Clin Nutr 2010, 64:289-296.

23. Ng TP, Feng L, Niti M, Kua EH, Yap KB: Folate, vitamin B12, homocysteine, and depressive symptoms in a population sample of older Chinese adults. J Am Geriatr Soc 2009, 57:871-876.

24. Ramos MI, Allen LH, Haan MN, Green R, Miller JW: Plasma folate concentrations are associated with depressive symptoms in elderly Latina women despite folic acid fortification. Am J Clin Nutr 2004, 80:1024-1028.

25. Sachdev PS, Parslow RA, Lux O, Salonikas C, Wen W, Naidoo D, Christensen $\mathrm{H}$, Jorm AF: Relationship of homocysteine, folic acid and vitamin B12 with depression in a middle-aged community sample. Psychol Med 2005, 35:529-538.

26. Sánchez-Villegas A, Doreste J, Schlatter J, Pla J, Bes-Rastrollo M, MartínezGonzález MA: Association between folate, vitamin B(6) and vitamin $B(12)$ intake and depression in the SUN cohort study. J Hum Nutr Diet 2009, 22:122-133.

27. Tiemeier H, van Tuijl HR, Hofman A, Meijer J, Kiliaan AJ, Breteler MM: Vitamin B12, folate, and homocysteine in depression: the Rotterdam Study. Am J Psychiatry 2002, 159:2099-2101.

28. Tolmunen T, Hintikka J, Voutilainen S, Ruusunen A, Alfthan G, Nyyssonen K, Viinamaki H, Kaplan GA, Salonen JT: Association between depressive symptoms and serum concentrations of homocysteine in men: a population study. Am J Clin Nutr 2004, 80:1574-1578.

29. Levitt AJ, Joffe RT: Folate, B12, and life course of depressive illness. Biol Psychiatry 1989, 25:867-872

30. Fava M, Borus JS, Alpert JE, Nierenberg AA, Rosenbaum JF, Bottiglieri T: Folate, vitamin B12, and homocysteine in major depressive disorder. Am J Psychiatry 1997, 154:426-428.

31. Papakostas Gl, Petersen T, Mischoulon D, Ryan JL, Nierenberg AA, Bottiglieri T, Rosenbaum JF, Alpert JE, Fava M: Serum folate, vitamin B12, and homocysteine in major depressive disorder, Part 1: predictors of clinical response in fluoxetine-resistant depression. J Clin Psychiatry 2004, 65:1090-1095.

32. Papakostas Gl, Petersen T, Lebowitz BD, Mischoulon D, Ryan JL, Nierenberg AA, Bottiglieri T, Alpert JE, Rosenbaum JF, Fava M: The relationship between serum folate, vitamin B12, and homocysteine levels in major depressive disorder and the timing of improvement with fluoxetine. Int J Neuropsychopharmacol 2005, 8:523-528.

33. Papakostas Gl, Petersen T, Mischoulon D, Green CH, Nierenberg AA Bottiglieri T, Rosenbaum JF, Alpert JE, Fava M: Serum folate, vitamin B12, and homocysteine in major depressive disorder, Part 2: predictors of relapse during the continuation phase of pharmacotherapy. J Clin Psychiatry 2004, 65:1096-1098.

34. Murakami K, Mizoue T, Sasaki S, Ohta M, Sato M, Matsushita Y, Mishima N: Dietary intake of folate, other B vitamins, and omega-3 polyunsaturated fatty acids in relation to depressive symptoms in Japanese adults. Nutrition 2008, 24:140-147.

35. Tolmunen T, Hintikka J, Ruusunen A, Voutilainen S, Tanskanen A, Valkonen VP, Viinamaki H, Kaplan GA, Salonen JT: Dietary folate and the risk of depression in Finnish middle-aged men. A prospective follow-up study. Psychother Psychosom 2004, 73:334-339.

36. Skarupski KA, Tangney C, Li H, Ouyang B, Evans DA, Morris MC: Longitudinal association of vitamin B-6, folate, and vitamin B-12 with depressive symptoms among older adults over time. Am J Clin Nutr 2010 92:330-335.

37. Walker JG, Mackinnon AJ, Batterham P, Jorm AF, Hickie I, McCarthy A, Fenech $\mathrm{M}$, Christensen $\mathrm{H}$ : Mental health literacy, folic acid and vitamin 
B12, and physical activity for the prevention of depression in older adults: randomised controlled trial. Br J Psychiatry 2010, 197:45-54.

38. Radimer K, Bindewald B, Hughes J, Ervin B, Swanson C, Picciano MF: Dietary supplement use by US adults: data from the National Health and Nutrition Examination Survey, 1999-2000. Am J Epidemiol 2004, 160:339-349.

39. Li C, Barker L, Ford ES, Zhang X, Strine TW, Mokdad AH: Diabetes and anxiety in US adults: findings from the 2006 Behavioral Risk Factor Surveillance System. Diabet Med 2008, 25:878-881.

40. Mokdad AH, Stroup DF, Giles WH: Public health surveillance for behavioral risk factors in a changing environment. Recommendations from the Behavioral Risk Factor Surveillance Team. MMWR Recomm Rep 2003, 52:1-12.

41. Nelson DE, Holtzman D, Bolen J, Stanwyck CA, Mack KA: Reliability and validity of measures from the Behavioral Risk Factor Surveillance System (BRFSS). Soc Prev Med 2001, 46(Suppl 1):S3-42.

42. Nelson DE, Powell-Griner E, Town M, Kovar MG: A comparison of national estimates from the National Health Interview Survey and the Behavioral Risk Factor Surveillance System. Am J Public Health 2003, 93:1335-1341.

43. Satia-Abouta J, Patterson RE, King IB, Stratton KL, Shattuck AL, Kristal AR, Potter JD, Thornquist MD, White E: Reliability and validity of self-report of vitamin and mineral supplement use in the vitamins and lifestyle study. Am J Epidemiol 2003, 157:944-954.

44. Strine TW, Mokdad AH, Dube SR, Balluz LS, Gonzalez O, Berry JT, Manderscheid R, Kroenke $K$ : The association of depression and anxiety with obesity and unhealthy behaviors among community-dwelling US adults. Gen Hosp Psychiatry 2008, 30:127-137.

45. Strine TW, Mokdad AH, Balluz LS, Gonzalez O, Crider R, Berry JT, Kroenke K: Depression and anxiety in the United States: findings from the 2006 Behavioral Risk Factor Surveillance System. Psychiatr Serv 2008, 59:1383-1390.

46. Cannon DS, Tiffany ST, Coon H, Scholand MB, McMahon WM, Leppert MF: The PHQ-9 as a brief assessment of lifetime major depression. Psychol Assess 2007, 19:247-251.

47. Kroenke K, Spitzer RL, Williams JB: The PHQ-9: validity of a brief depression severity measure. J Gen Intern Med 2001, 16:606-613.

48. Martin A, Rief W, Klaiberg A, Braehler E: Validity of the Brief Patient Health Questionnaire Mood Scale (PHQ-9) in the general population. Gen Hosp Psychiatry 2006, 28:71-77.

49. Pinto-Meza A, Serrano-Blanco A, Penarrubia MT, Blanco E, Haro JM: Assessing depression in primary care with the PHQ-9: can it be carried out over the telephone? J Gen Intern Med 2005, 20:738-742.

50. Brocardo PS, Budni J, Kaster MP, Santos AR, Rodrigues AL: Folic acid administration produces an antidepressant-like effect in mice: evidence for the involvement of the serotonergic and noradrenergic systems. Neuropharmacology 2008, 54:464-473.

51. Passeri M, Cucinotta D, Abate G, Senin U, Ventura A, Stramba BM, Diana R, La GP, Le GC: Oral 5'-methyltetrahydrofolic acid in senile organic mental disorders with depression: results of a double-blind multicenter study. Aging (Milano) 1993, 5:63-71.

52. Alpert JE, Mischoulon D, Rubenstein GE, Bottonari K, Nierenberg AA, Fava M: Folinic acid (Leucovorin) as an adjunctive treatment for SSRIrefractory depression. Ann Clin Psychiatry 2002, 14:33-38.

53. Alpert M, Silva RR, Pouget ER: Prediction of treatment response in geriatric depression from baseline folate level: interaction with an SSRI or a tricyclic antidepressant. J Clin Psychopharmacol 2003, 23:309-313.

54. Coppen A, Bailey J: Enhancement of the antidepressant action of fluoxetine by folic acid: a randomised, placebo controlled trial. $J$ Affect Disord 2000, 60:121-130.

55. Fava M: Augmenting antidepressants with folate: a clinical perspective. $J$ Clin Psychiatry 2007, 68(Suppl 10):4-7.

56. Morris DW, Trivedi MH, Rush AJ: Folate and unipolar depression. J Altern Complement Med 2008, 14:277-285.

57. Taylor MJ, Carney SM, Goodwin GM, Geddes JR: Folate for depressive disorders: systematic review and meta-analysis of randomized controlled trials. J Psychopharmacol 2004, 18:251-256.

58. Satia-Abouta J, Kristal AR, Patterson RE, Littman AJ, Stratton KL, White E: Dietary supplement use and medical conditions: the VITAL study. Am J Prev Med 2003, 24:43-51.
59. Horwath E, Johnson J, Klerman GL, Weissman MM: Depressive symptoms as relative and attributable risk factors for first-onset major depression. Arch Gen Psychiatry 1992, 49:817-823.

60. Hintikka J, Tolmunen T, Tanskanen A, Viinamaki H: High vitamin B12 level and good treatment outcome may be associated in major depressive disorder. BMC Psychiatry 2003, 3:17-22.

61. Hvas AM, Juul S, Bech P, Nexo E: Vitamin B6 level is associated with symptoms of depression. Psychother Psychosom 2004, 73:340-343.

62. Obeid R, McCaddon A, Herrmann W: The role of hyperhomocysteinemia and B-vitamin deficiency in neurological and psychiatric diseases. Clin Chem Lab Med 2007, 45:1590-1606.

doi:10.1186/1475-2891-10-102

Cite this article as: Zhao et al: Use of folic acid and vitamin

supplementation among adults with depression and anxiety: a crosssectional, population-based survey. Nutrition Journal 2011 10:102.

\section{Submit your next manuscript to BioMed Central and take full advantage of:}

- Convenient online submission

- Thorough peer review

- No space constraints or color figure charges

- Immediate publication on acceptance

- Inclusion in PubMed, CAS, Scopus and Google Scholar

- Research which is freely available for redistribution 